$11-4-2013$

\title{
Conceptualizing Communication Capital for a Changing Environment
}

Leo Wayne Jeffres

Cleveland State University, I.jeffres@csuohio.edu

Guowei Jian

Cleveland State University, g.jian@csuohio.edu

Sukki Yoon

Bryant University, syoon@bryant.edu

Follow this and additional works at: https://engagedscholarship.csuohio.edu/clcom_facpub

Part of the Civic and Community Engagement Commons, and the Social Influence and Political Communication Commons

How does access to this work benefit you? Let us know!

Publisher's Statement

This is an Author's Accepted Manuscript of an article published in Communication Quarterly 11-04-2013, available online: http://www.tandfonline.com/10.1080/01463373.2013.806336

\section{Recommended Citation}

Jeffres, L. W., Jian, G., \& Yoon, S. (2013). Conceptualizing communication capital for a changing environment. Communication Quarterly, 61(5), 539-563. doi:10.1080/01463373.2013.806336

This Article is brought to you for free and open access by the School of Communication at EngagedScholarship@CSU. It has been accepted for inclusion in Communication Faculty Publications by an authorized administrator of EngagedScholarship@CSU. For more information, please contact library.es@csuohio.edu. 


\title{
Conversation at Work: The Effects of Leader-Member Conversational Quality
}

\author{
Guowei Jian' and Francis Dalisay²
}

\begin{abstract}
Although research has made significant gains in understanding the constitutive nature of conversation in the process of organizing, its predictive effects on organizational outcomes are still uncertain. To contribute in this direction, based on social exchange theory and leader-member exchange (LMX) research, this study examined the predictive effects of leader-member conversational quality (LMCQ) on employee organizational commitment $(\mathrm{OC})$, and the potential interaction effects of LMCQ with LMX quality. Using data from an online survey, this study found that above and beyond communication frequency and other control variables, LMCQ is significantly associated with employee OC. More interestingly, the effects of LMCQ vary based on the level of LMX quality. These findings have significant implications at both theoretical and practical levels.
\end{abstract}

\section{Keywords}

leadership, leader-member exchange, supervisor-subordinate communication, conversation, organizational commitment

Research continues to reveal the central role of conversation in various organizing processes (Ashcraft, Kuhn, \& Cooren, 2009; Boden, 1994; Taylor \& Van Every, 2000). For example, Taylor and Van Every (2000) convincingly presented a theoretical account explaining that organization is emergent in conversation and text. Empirically,

'Cleveland State University, OH, USA

¿University of Hawai'i-Manoa, USA

Corresponding Author:

Guowei Jian, School of Communication, Cleveland State University, 212I Euclid Ave., MU247, Cleveland, $\mathrm{OH} 44 I 15$, USA.

Email: g.jian@csuohio.edu 
organizational discourse studies have painstakingly demonstrated the role of conversation in change management (e.g., Jian, 2011) and leadership processes (e.g., Fairhurst, 2007). In spite of such exciting progress so far, it still remains inconclusive whether and how conversations influence various aspects of organizational outcomes, both behavioral and attitudinal. Indeed, few studies have examined such processes from a quantitative approach. Although qualitative analyses, particularly, discourse studies, afford researchers the ability to depict the fine details of discursive practices and processes, quantitative approaches would allow researchers to draw inferential statistical conclusions regarding potential associations between conversational practices and organizational outcomes (Jian, Shi, \& Dalisay, 2014). To pursue the latter, the present study focuses on analyzing the predictive effects of conversational quality in leader-member dyads.

More specifically, the purpose of the present study is to examine the way in which leader-member conversational quality (LMCQ) interacts with leader-member exchange (LMX) quality to predict member organizational commitment (OC). This study contributes to the existing literature in four aspects. First, this study extends the LMX theory of leadership by offering a more nuanced theoretical account for the way in which conversations may function in relationship development and influence employee attitudinal outcomes. Second, this study provides much-needed quantitative evidence for the role of conversational practices in the workplace. Third, the findings offer further confirmation of the validity and reliability of the newly developed LMCQ scale (Jian et al., 2014). Finally, at the practical level, the findings of this study could be used to inform managers that being mindful in their everyday conversations with employees and developing conversational skills may help foster productive working relationships and employee commitment.

The remainder of this article first provides the theoretical context and rationalization of the proposed hypotheses. Next, the article details the study's methodology. Finally, findings and a discussion of their significance and limitations are presented.

\section{LMX, Communication, and Conversation}

Among various approaches to organizational leadership, the LMX approach remains vibrant after nearly four decades of tremendous growth (Anand, Hu, Liden, \& Vidyarthi, 2011; Dulebohn, Bommer, Liden, Brouer, \& Ferris, 2012). Unlike many other approaches that focus heavily on leaders' cognition and behavior, LMX pays attention to the relational dynamic between leaders and members (Graen \& Uhl-Bien, 1995). More importantly, the LMX theory maintains that the relationship quality between a leader and his or her various members could be located on a continuum from low to high. Different levels of relationship quality carry different relational properties (Graen \& Uhl-Bien, 1995). For example, low-quality LMX relationships are characterized as having low levels of trust and support, and the exchange process is based on employment contracts. Moreover, in low-quality LMX relationships, tasks are often given and carried out based on job descriptions. In contrast, high-quality LMX relationships are characterized by high levels of trust and support and members 
tend to have more negotiation latitude in task assignment; the high-quality exchange process goes beyond economic exchange and has more social and emotional elements than in low-quality relationships (Bernerth, Armenakis, Feild, Giles, \& Walker, 2007). Empirical research lends strong support for the benefit of high-quality LMX relationships, such as greater job satisfaction and OC by employees (for review, see Anand et al., 2011; Dulebohn et al., 2012; Gerstner \& Day, 1997; Van Breukelen, Schyns, \& Le Blanc, 2006).

Within the broader LMX leadership research, as briefly reviewed above, the role of communication in the development and outcomes of LMX has gained sustained attention from scholars over the years. Four primary lines of research regarding communication in LMX relationships have emerged. The first line of studies conceptualizes communication between leaders and members as strategic choices. The primary concern for scholars is to describe communication tactics and the antecedents and outcomes of their use in upward influence and relationship maintenance (Krone, 1991; Lee \& Jablin, 1995; Olufowote, Miller, \& Wilson, 2005; Waldron, 1991; Waldron \& Sanderson, 2011). For instance, Olufowote et al. (2005) analyzed the communication tactics employees used to initiate role change as a form of upward influence. The researchers found that LMX moderates the association of role change magnitude and the use of rationality as a communication tactic. In particular, for low-quality LMX dyads, the greater the role change sought, the higher is the likelihood of using rationality for a method of persuasion, whereas this association becomes negative for highquality LMX dyads.

The second line of research examines the patterns of communication in terms of content and style across different levels of LMX relationships. This stream of investigations often conceptualizes communication patterns in such dichotomized patterns as cooperative versus competitive communication (Lee, 2001) and person-centered versus position-centered communication (Fix \& Sias, 2006). Lee (2001) examined the correlation between cooperative communication, LMX, and perception of organizational justice. Although Lee did not directly test a moderating effect of LMX, the conceptual discussion in Lee's study suggested that a stronger relationship between cooperative communication and perceived organizational justice could result as an LMX relationship moves from low to high levels. This assumes that there are more opportunities for employee input in decisions and more feedback from supervisors in higher levels of LMX. In another study, Fix and Sias (2006) argued that communication styles of supervisors, such as person-centered communication, could be considered as a communication resource at the disposal of supervisors. The study found that greater expectations of person-centered communication are directly associated with subordinates' perceptions of job satisfaction. From this resource-based view, it can be reasoned that, as the condition of LMX changes from low to high, communication resources including person-centered communication increase, and the positive effects on individual work outcomes also increase.

The third line of research addresses the quality and amount of communication in relation to LMX relationships. For example, Sias (2005) investigated the predictive effects of the amount and quality of work-related information received by employees 
from their supervisors on LMX. The findings provided support that higher LMX is associated with both the quantity and quality of information employees receive from their supervisors. In addition, the study revealed that information quality is also a significant predictor of employees' OC. Although in line with the past findings on the connection between LMX and OC, the study showed that information quality is a much stronger predictor of commitment than LMX, and suggested "[a] need for future communication-centered research examining LMX theory" (p. 388). In another study, Mueller and Lee (2002) examined the association between LMX and employee communication satisfaction, the latter of which refers to the quality and amount of information they receive. As predicted, higher levels of satisfaction with the quality and amount of information from supervisors are positively associated with higher levels of LMX quality.

In sum, the research thus far has investigated the effects of communication in relation to LMX and other organizational outcomes from various angles, including communication tactics, communication styles, and information quality and quantity. In spite of these advancements, the processes and effects of conversation in organizing are not satisfactorily understood. Taylor and Van Every (2000) theorized that conversation is part of the mechanisms in which an organization is realized. Because leadermember communication largely takes place in everyday conversations at work, whether and how leader-member conversations impact relationship and other outcome variables deserve closer scrutiny.

Fairhurst's (1993) groundbreaking studies on conversational practices in LMX have produced exciting initial results. Taking a qualitative approach, her research focused on the construction of LMX conversational patterns, particularly, the negotiation of meaning, the use of conversational resources, and patterns of conversational moves. For example, by analyzing audio recordings of leader-member conversations, Fairhurst identified various conversational patterns that differentiate high LMX relationships from low LMX relationships. In particular, she found that high and medium LMX dyads are characterized by aligning conversational moves, such as "spiraling agreement pattern" and "acceptable face-threatening humor by member," that minimize power differences. On the other hand, low LMX dyads tend to enact polarizing behaviors, such as "interruptions" and "control orientation," that maximize power differences.

Fairhurst's study reveals the complex conversational moves that leaders and members take to construct relationships. Although such a qualitative, discursive approach offers a detailed, microscopic look at relational construction and meaning negotiation through conversations, the predictive effects of work conversations on relational and organizational outcomes demand further theorizing and empirical testing. The field would benefit from quantitative analyses that allow for statistical assessments of conversational practices and permit testing and statistical assessment of inferential associations between conversational practices, relational quality, and other organizational constructs (Jian et al., 2014). In the following, we argue that LMCQ as a construct, together with its newly developed measure (Jian et al., 2014), provides an opportunity 
for researchers to theorize the role of conversation with regard to LMX and other organizational outcomes - in particular, employee OC.

\section{LMCQ and LMX}

As we suggested earlier, LMX quality as a construct denotes the overall perception regarding a dyadic leader-member relationship, which is largely cognitive and affective (Bernerth et al., 2007). This is apparent in how the LMX construct has been operationalized in various studies. For example, in the most popular seven-item LMX measure, known as LMX7, an item reads, "I usually know where I stand with my supervisor." In the multidimensional measure of LMX (LMX-MDM) developed by Liden and Maslyn (1998), a sample item states, "I admire my supervisor's professional skills." In a more recently developed Leader-Member Social Exchange scale by Bernerth et al. (2007), a representative statement reads, "When my supervisor gives me support, I feel I owe it to him or her to return the favor." As suggested in these examples, these extant measures of LMX quality do not satisfactorily capture the conversational quality within a leader-member dyad, nor do they provide any conversational level assessment. By contrast, LMCQ, as shown below, provides a more in-depth conceptualization and assessment of leader-member communicative exchange (Jian et al., 2014).

According to Jian et al. (2014), LMCQ refers to the richness of the conversation in a leader-member dyad in the context of accomplishing work tasks. LMCQ was developed based on the interaction richness theory (Barry \& Crant, 2000). According to Barry and Crant (2000), conversational interaction is central to dyadic work relationships, especially in the context of accomplishing tasks. Rich interaction is characterized by three properties. The first is efficiency, which refers to the ease in both meaning interpretation and information exchange. Efficiency is marked by the fact that the dyadic members are able to convey more meaning but with fewer words. As they described, a dyadic interaction is efficient when the conversational exchange is "high in informational and symbolic content" (Barry \& Crant, 2000, p. 651). The second property of a rich conversational interaction is coordination. Well-coordinated interaction results from the alignment of meaning systems, norms, and expectancies. Punctuation and synchronized moves between dyadic members are signs of good coordination and, hence, high-quality conversation. The third property of richness is the accuracy in meaning interpretation. According to Jian et al. (2014), this property refers to the extent to which leaders and members precisely convey and interpret messages regarding task assignments and work feedback. Taken together, LMCQ is defined by efficiency, coordination, and accuracy in both transferring information and interpreting meaning in the context of fulfilling work objectives (Jian et al., 2014).

\section{Hypothesis Development}

Prior studies have shown significant predictive effects of various aspects of communication on employee OC. For example, De Ridder (2004) demonstrated that the quality 
of task-related information is positively associated with OC (De Ridder, 2004). Mathieu and Zajac (1990) identified leader communication as a strong predictor of employee OC. In particular, they suggested that accurate and timely communication by supervisors helps improve perceptions of the work environment and thereby positively influences employee commitment to the organization.

The present study furthers this line of argument by pinpointing the role of conversational quality in communication between leaders and members. As Eisenberger, Huntington, Hutchison, and Sowa (1986) argued, leaders are proxies for organizations. Leaders are given the role to instill the values and responsibilities in members' minds, which is the realization of commitment. We argue that, to a large extent, the transference and convergence of values at the normative level between organizations and members have to be realized in conversations between leaders and members in their immediate routine work contexts. Accuracy in conversations enhances employees' understanding of work goals and values. We also argue that accuracy, efficiency, and coordination in conversations help affirm both one's feeling of self-efficacy as a competent member of the organization and the efficacy of a leader-member dyad as a synchronized unit capable of executing tasks at hand. Presumably, such affirmations can engender a feeling of communication satisfaction, which has been shown to be positively associated with person-organization fit and a feeling of commitment to the organization (Carrière \& Bourque, 2009; Downs et al., 1995; Van Vuuren, De Jong, \& Seydel, 2007; Varona, 1996). Thus, we propose our first hypothesis:

Hypothesis 1: Members' perception of LMCQ has a positive association with members' OC.

In addition, we argue that the association between LMCQ and employee OC is moderated by LMX quality. In other words, we propose that the predictive effect of LMCQ on employee commitment varies as the level of LMX relationship quality changes. Our reasoning is largely based on social exchange theory (Blau, 1964; Cropanzano \& Mitchell, 2005) and LMX theory (Graen \& Uhl-Bien, 1995). Based on social exchange theory, there are two types of transactions between individuals: economic and social exchange. These two types of transactions differ in rules and transacted resources. For economic exchanges, rules are based on negotiated agreements that tend to be detailed and explicit (Cropanzano \& Mitchell, 2005). An employment contract is an example of a negotiated agreement containing economic exchange rules. A contract explicitly defines the resources required for transactions, such as work time in exchange for financial rewards. For social exchanges, on the other hand, the rules for transactions tend to be more implicit. Reciprocity, for example, is a commonly observed rule of social exchange. Reciprocity implicitly guides a relationship through transactions of less specified resources, such as loyalty and trust, which, unlike time and monetary rewards, are intangible and particularistic to individuals involved in a relationship (Blau, 1964).

In economic transactions, the meanings of actions tend to be explicitly spelled out in an agreed work contract, and the demand for conversation and interpretation to 
execute a transaction is less than that in social exchange relationships. By contrast, because of the implicit nature of the rules and the particularistic and intangible nature of the resources in social exchange relationships, we argue that successful social changes do not simply happen automatically with correct cognitive calculations made by both parties. Instead, social interactions in the form of conversations facilitate social exchanges through negotiations and interpretations of rules and resources. For example, when a leader assigns a nonroutine task to a member and the member volunteers to work overtime on the task, the content of the task, the meaning of the assignment, and the resources it may require have to be talked about and mutually understood for the task to be successfully carried out. For the exchange to be interpreted as "fair," the intended symbolic meanings of the assignment by the leader (e.g., trust) and the volunteering action by the member (e.g., diligence and loyalty) have to be properly grasped by both parties. Higher quality conversations, we argue, enhance the precision of interpretations and better facilitate a mutually satisfying social exchange.

Furthermore, as we reviewed earlier, LMX theory specifies that low- and highquality LMX relationships are characterized by economic and social transactions, respectively. One particular characteristic that differentiates the relationship is negotiation latitude. Research has long established that members in low LMX relationships have less negotiation latitude than those in high LMX relationships (Dansereau, Graen, \& Haga, 1975). Having greater negotiation latitude implies more opportunities for the two parties to engage in conversations and influence each other. Fairhurst (1993) confirmed that members in higher quality LMX dyads are involved more in conversations and mutual persuasion. Through conversations, leaders and members negotiate individual objectives and resources, establish common goals, and adjust rules of exchange. It is reasonable to assume that quality conversations enable social exchange and positively impact its outcome. Thus, as a leader-member relationship moves from low to high quality, and with the increasing opportunities for negotiations and social exchange, we argue that conversational quality in the relationship matters more in affecting individual perceptions of satisfaction and support. From the social exchange perspective, greater commitment could be understood as an outcome of a reciprocal transaction with a greater sense of satisfaction and support. Thus, it stands to reason that the effect of conversational quality on OC would be greater as LMX relationship quality increases. Therefore, we propose our second hypothesis.

Hypothesis 2: There is a moderating effect of LMX on the association between members' perception of LMCQ and members' OC such that LMCQ is more strongly related to members' OC as perceived LMX quality increases.

\section{Method}

\section{Sample and Data Collection}

The study used a sample of employees of various organizations. These employees were recruited through the networks of students enrolled in classes of a public 
university in a large Midwestern metropolitan area in the United States. In exchange for extra credit, students were asked to refer an online survey to participants who have been in a full-time job for at least the past 6 months and who have had one direct supervisor at this job for at least the past 6 months. A similar sampling strategy has been used in other studies with the goal of covering a wide range of jobs (Harvey \& Harris, 2010; Jian, 2014; Sin, Nahrgang, \& Morgeson, 2009).

The study received 209 survey responses in total. After deleting incomplete cases, we obtained 172 usable survey responses. Among the sample, 39\% were males and $60 \%$ females. This biological sex composition reflects the higher representation of employees from such industry sectors as education (19\%), retail (16\%), and health services (13\%). The average age of participants was 34. Among them, $63 \%$ were White/Caucasian, 24\% Black/African American, 5\% Hispanic, 3\% Asian, and 5\% Mixed or Other races. Participants reported an average tenure of 7.23 years with their current organization and average time of 3.40 years working with their current direct supervisor.

\section{Measurement Instruments}

LMX. To measure LMX, the leader-member social exchange scale (Bernerth et al., 2007) was adopted. Although LMX7 (Scandura \& Graen, 1984) and LMX-MDM (Liden \& Maslyn, 1998) have been widely used in the existing literature, these measures largely tap into the affective aspect of relationship quality and fail to operationalize the social exchange process (Anand et al., 2011; Bernerth et al., 2007). The leader-member social exchange scale was established to assess social exchange between leaders and members and has been shown to possess sound psychometric properties (Bernerth et al., 2007). A sample item is, "I do not have to specify the exact conditions to know my supervisor will return a favor." The measure has 8 items and uses a seven-point Likert-type scale from 1 being strongly disagree to 7 being strongly agree. The Cronbach's alpha for the scale in Bernerth et al. (2007) was .92. In the present study, the Cronbach's alpha was .94.

LMCQ. To measure LMCQ, the study adopted the LMCQ scale (Jian et al., 2014). The LMCQ scale was composed of nine items (Jian et al., 2014), which were based on Barry and Crant's (2000) construct of interactional richness of communication as discussed earlier. LMCQ demonstrated sound psychometric properties (Jian et al., 2014). Jian et al. (2014) reported a Cronbach's alpha of .96. A sample item reads, "My supervisor and I interpret each other's ideas accurately when discussing work-related matters." The measure used a seven-point Likert-type scale from 1 being strongly disagree to 7 strongly agree. The Cronbach's alpha in the present study was .96 .

OC. The study adopted Mowday, Steers, and Porter's (1979) organizational commitment questionnaire. The instrument has nine items. One sample item states, "I am willing to put in a great deal of effort beyond that normally expected in order to help this organization be successful." Like LMCQ, a seven-point Likert-type scale was 
used from 1 being strongly disagree to 7 strongly agree. The Cronbach's alpha in the present study was .92 .

Control variables. We controlled for several variables, including age dissimilarity, biological sex dissimilarity, race dissimilarity, organizational tenure, time with supervisor, and communication frequency with supervisor. First, we included demographic dissimilarity because, based on the literature of relational demography (Abu Bakar, Jian, \& Fairhurst, 2014; Tsui \& Gutek, 1999; Tsui \& O’Reilly, 1989; Tsui, Porter, \& Egan, 2002) in leader-member relational studies, demographic dissimilarities (or similarities) matter more than individual demographics in shaping relational outcomes at both attitudinal and behavioral levels. Second, organizational tenure has been shown to be associated with OC in previous research (Mathieu \& Zajac, 1990). Similarly, we suspect that time with supervisor could be associated with the perception of social exchange and conversational quality. Third, different jobs may require different levels of communication frequency and previous studies have demonstrated significant effects of communication frequency on LMX (Kacmar, Witt, Zivnuska, \& Gully, 2003). Hence, we included communication frequency as a control variable as well. The instrument for communication frequency, as used by Kacmar et al. (2003), includes four items, such as, "How often do you and your supervisor talk at work?"

\section{Data Analysis}

Data analysis proceeded in two steps: preliminary and primary. In preliminary analyses, using Amos Version 18, we first conducted confirmatory factor analyses on the measurement instruments of the three primary constructs in order to confirm their dimensionality in the present data set. Second, we conducted correlational analyses among the test variables. Third, we tested for any potential common method bias, which could be caused by the fact that the data were collected through self-reports from the same source (Podsakoff, MacKenzie, Lee, \& Podsakoff, 2003).

For primary analyses, hierarchical regression analyses were used to test Hypothesis 1. Significant correlations among test variables may cause concern for multicollinearity. To address this concern, we used mean deviations of test variables for regression analyses (Cohen, Cohen, West, \& Aiken, 2013; Jaccard \& Turrisi, 2003). OC was regressed on the control variables (Step 1) and then on LMX (Step 2). To test Hypothesis 1 regarding the effect of LMCQ, OC was regressed on the control variables (Step 1), LMX (Step 2), and LMCQ (Step 3). To test Hypothesis 2 regarding the interactive effect of LMX and LMCQ on OC, we used Hayes's PROCESS macro for SPSS (Hayes, 2014). Hayes's PROCESS macro also allowed us to further probe the interaction in order to ascertain whether and how LMCQ is related to OC at various levels of LMX. The PROCESS macro is especially advantageous in the task of probing an interaction because it allows tests of significant interactions at the 10th, 25th, 50th, 75th, and 90th percentile of the distribution of a moderator (Hayes, 2014). By contrast, the conventional approaches for such probing that use a standard deviation above and below the mean, or mean- or median-split, may involve values that are 
beyond the actual range of values for the variables and distort true effects (Hayes, 2014). Thus, the percentile approach not only effectively avoids this problem but also provides a more detailed picture of the moderation to aid interpretation.

\section{Results}

\section{Preliminary Analyses}

To check the dimensionality of the measurement instruments, confirmatory factor analyses (CFAs) were performed. For LMX, CFA results showed adequate goodnessof-fit $\left(\chi^{2}=38.113, d f=17, p=.002\right.$, goodness-of-fit index $[\mathrm{GFI}]=.944$, normed fit index $[\mathrm{NFI}]=.965$, comparative fit index $[\mathrm{CFI}]=.980$, root mean square error of approximation $[\mathrm{RMSEA}]=.085$ ). For LMCQ, CFA results demonstrated good fit $\left(\chi^{2}\right.$ $=38.477, d f=25, p=.042, \mathrm{GFI}=.954, \mathrm{NFI}=.976, \mathrm{CFI}=.991, \mathrm{RMSEA}=.056)$. For OC, CFA results showed good fit as well $\left(\chi^{2}=39.615, d f=25, p=.032\right.$, GFI $=.950$, $\mathrm{NFI}=.959, \mathrm{CFI}=.984, \mathrm{RMSEA}=.058)$. These findings confirmed the unidimensionality of the instruments as posited. Based on these results, scales were constructed to measure LMX, LMCQ, and OC.

Next, we computed descriptive statistics and a correlational matrix as displayed in Table 1. As shown, the correlations between LMX, LMCQ, and OC were significant, even after accounting for the effects of control variables. Both $\operatorname{LMX}(r=.44, p<.001)$ and LMCQ $(r=.51, p<.001)$ had moderate positive correlations with OC. It is noticeable that LMX and LMCQ had high correlations $\left(r=.80, p<.001 ; r_{\text {partial }}=.76, p<\right.$ $.001)$. Also noticeable were the significant positive correlations between communication frequency and LMX $(r=.42, p<.001)$, LMCQ $(r=.46, p<.001)$, and OC $(r=$ $.36, p<.001)$, respectively.

To diagnose potential common method bias, first, a one-factor model was tested for its goodness-of-fit with all of the 26 indicators of LMX, LMCQ, and OC loaded on one factor. The CFA test showed poor model fit $\left(\chi^{2}=1145.706, d f=292, p=.000\right.$, $\mathrm{GFI}=.562, \mathrm{NFI}=.729, \mathrm{CFI}=.781, \mathrm{RMSEA}=.131)$. Next, we tested a three-factor model with LMX, LMCQ, and OC as distinct factors. The results indicated very significant improvement in goodness-of-fit $\left(\chi^{2}=464.870, d f=289, p=.000, \mathrm{GFI}=.837\right.$ $\mathrm{NFI}=.890, \mathrm{CFI}=.955, \mathrm{RMSEA}=.060)$ with $\Delta \chi^{2}(3)=680.836, p<.001$.

In addition, because LMX and LMCQ had a rather high correlation, we further tested whether LMX and LMCQ were discriminant by comparing two models: a twofactor model in which OC as Factor 1 and indicators of LMX and LMCQ were combined as Factor 2, and a three-factor model, in which LMX, LMCQ, and OC were three separate factors. For LMX and LMCQ to be discriminant, the two-factor model was expected to be significantly less fit than the three-factor model. The test results provided confirmation that the two-factor model were significantly less fit than the three-factor model $\left(\chi^{2}=645.284, d f=290, p=.000, \mathrm{GFI}=.746, \mathrm{NFI}=.847, \mathrm{CFI}=\right.$ .909 , RMSEA $=.085)$ with $\Delta \chi^{2}(1)=180.414, p<.001$. To further assure that LMCQ and LMX are discriminant measures, we conducted another test as suggested by Bagozzi and Phillips (1982). This test compared the $\chi^{2}$ of two CFA models: Model A 


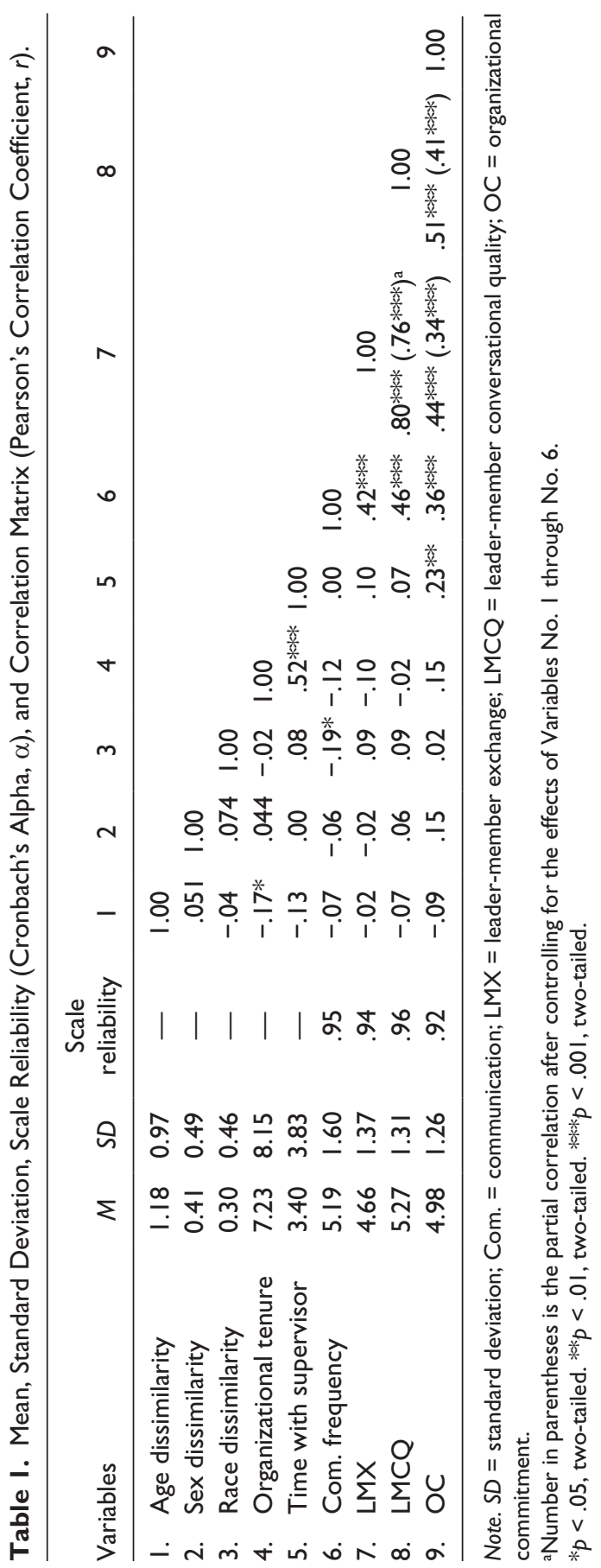


Table 2. Results of Hierarchical Regression Analyses (Models I-3) and Implementation of Hayes's PROCESS Macro for SPSS (Model 4).

\begin{tabular}{|c|c|c|c|c|}
\hline \multirow[b]{3}{*}{$\beta$} & \multicolumn{4}{|c|}{ Organizational commitment } \\
\hline & \multicolumn{4}{|c|}{ Model } \\
\hline & 1 & 2 & 3 & $4^{a}$ \\
\hline \multicolumn{5}{|l|}{ Control } \\
\hline Age dissimilarity & -.00 & -.01 & -.00 & -.01 \\
\hline Sex dissimilarity & $.15^{*}$ & $.16 *$ & $.13^{*}$ & $.36^{*}$ \\
\hline Race dissimilarity & .07 & .02 & -.01 & -.01 \\
\hline Organizational tenure & .10 & $.15^{\mathrm{b}}$ & .11 & .02 \\
\hline Time with supervisor & $.16^{c}$ & .12 & $.16 *$ & $.05^{*}$ \\
\hline Communication frequency & $.37 * * *$ & $.23 * *$ & $.16^{*}$ & $.12^{*}$ \\
\hline LMX & - & $.34 * * *$ & .06 & .04 \\
\hline LMCQ & - & - & $.38 * *$ & $.46 * * *$ \\
\hline $\mathrm{LMX} \times \mathrm{LMCQ}^{\mathrm{d}}$ & - & - & - & $.07^{*}$ \\
\hline$R^{2}\left(\operatorname{Adj} . R^{2}\right)$ & $.20(.17)$ & $.29(.26)$ & $.34(.30)$ & $.35(.32)$ \\
\hline$\Delta R^{2}$ & .20 & .09 & .05 & .02 \\
\hline$\Delta F$ & $6.63 * * *$ & $19.89 * * *$ & $10.47^{* *}$ & $4.4 I^{*}$ \\
\hline$d f$ & 6,158 & 7,157 & 8,156 & 9,155 \\
\hline
\end{tabular}

Note. $\mathrm{LMX}=$ leader-member exchange; LMCQ = leader-member conversational quality; OC = organizational commitment.

aThe interaction model (Model 4) was tested through Hayes's (2014) PROCESS Macro for SPSS.

$\mathrm{b} p=.07$.

$c p=.05$.

dThe product term represents the interaction effect of LMX and LMCQ on OC.

$*_{p}<.05 . * *_{p}<.01$. *** $p<.00 \mathrm{I}$.

$\left(\chi^{2}=277.43, d f=118, p=.000\right)$, in which LMCQ and LMX were unconstrained, and Model B $\left(\chi^{2}=287.39, d f=119, p=.000\right)$, in which LMCQ and LMX were constrained to equal 1.0 (Bagozzi \& Phillips, 1982). The comparison resulted in a significantly lower $\chi^{2}$ of Model A than Model B $\left(\Delta \chi^{2}(1)=9.96, p<.01\right)$, suggesting that LMCQ and LMX were indeed discriminant.

\section{Primary Analyses}

Table 2 shows the results from hierarchical regression analyses. First, the control variables were entered in Model 1. The model was significant $\left(\Delta R^{2}=.20\right.$, Adjusted $R^{2}=$ $.17, \Delta F=6.63, p<.001)$, showing both sex dissimilarity $(\beta=.15, t=2.09, p<.05)$ and communication frequency $(\beta=.37, t=5.04, p<.001)$ as significant predictors of OC. The effect of time with supervisor was approaching significance $(\beta=.16, t=1.98, p=$ $.05)$. In Model 2, LMX was entered, and the analysis $\left(\Delta R^{2}=.09\right.$, Adjusted $R^{2}=.26$, $\Delta F=19.89, p<.001)$ indicated that, after controlling for the effects of other variables in the model, LMX was a significant predictor of OC $(\beta=.34, t=4.46, p<.001)$. 


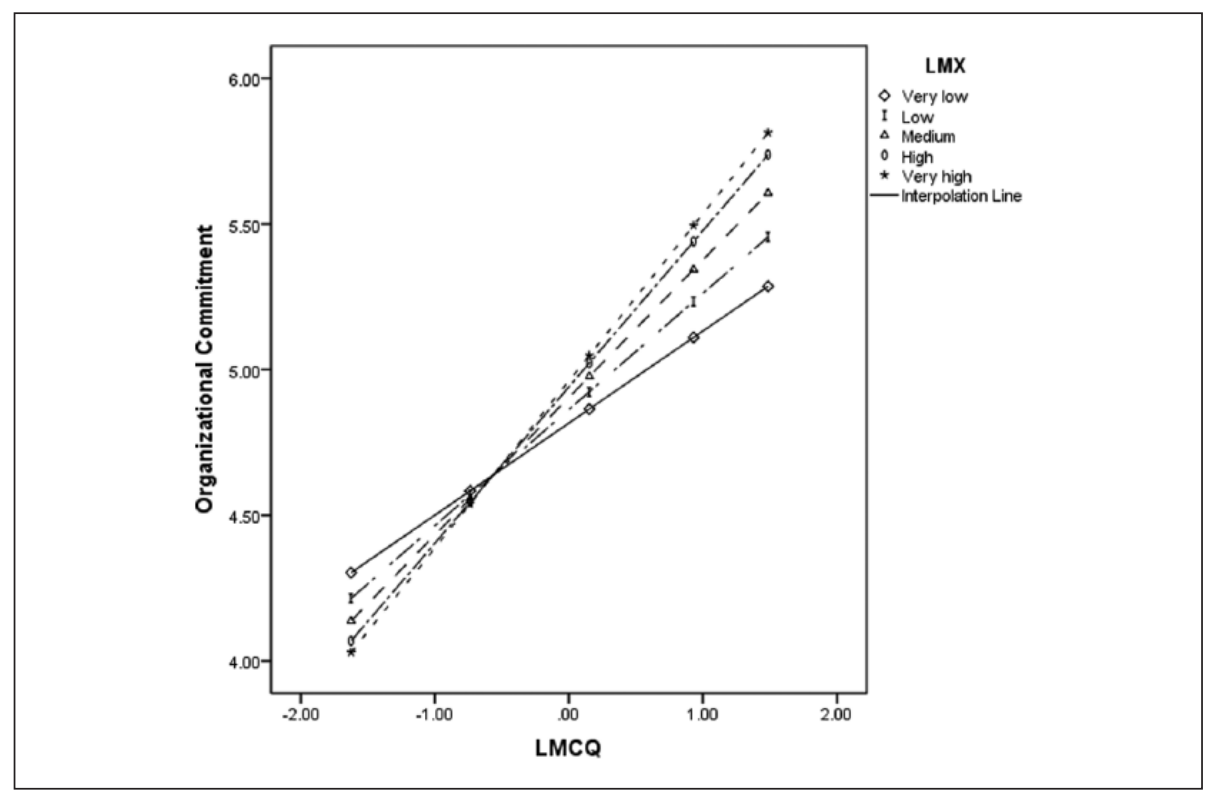

Figure I. The moderating effect of LMX on the association between LMCQ and organizational commitment.

Note. The range of LMCQ is based on mean-centered values. $L M X=$ leader-member exchange; $L M C Q=$ leader-member conversational quality.

Hypothesis 1 predicted that LMCQ and OC are positively associated. Results from Model $3\left(\Delta R^{2}=.05\right.$, Adjusted $\left.R^{2}=.30, \Delta F=10.47, p<.01\right)$ showed that beyond and above the effects of LMX and control variables, LMCQ was a significant predictor of OC $(\beta=.38, t=3.24, p<.01)$. Hence, Hypothesis 1 was supported. In addition, the fact that LMCQ appeared to be a significant predictor of OC above and beyond the effect of LMX provided further confirmation that LMCQ is a construct discriminant from LMX.

Hypothesis 2 predicted that there is a moderation effect of LMX on the association between LMCQ and OC such that the association becomes stronger as the level of LMX increases. To test this moderation effect, we ran Hayes's PROCESS macro for SPSS (Hayes, 2014). The test resulted in a significant change in variance explained by the moderation effect $\left(\Delta R^{2}=.02, \Delta F=4.41, p<.05\right)$. The moderation results are presented in Table 2 in the column of Model 4. Although $\Delta R^{2}$ was small, it was within the normal range (between .01 and .03) in testing moderation effects in social sciences with continuous predictor and outcome variables (Aiken \& West, 1991; Rogers, 2009). Above and beyond the effects of other variables in the model, the moderation effect was shown to be a significant predictor of OC $(\beta=.07, t=2.10, p<.05)$. A visual representation of the interaction model was produced through PROCESS as shown in Figure 1. The figure depicts a clear trend of stronger relationships between LMCQ and 
Table 3. Probing of Interaction: The Conditional Effects of LMCQ on Organizational Commitment at Different Values of the Moderator LMX.

\begin{tabular}{lccc}
\hline LMX & Effect & SE & $t$ \\
\hline 2.7I (the 10th percentile; very low) & .31 & .11 & $2.76^{\text {*** }}$ \\
3.84 (the 25th percentile; low) & .40 & .11 & $3.53^{\text {**** }}$ \\
4.84 (the 50th percentile; medium) & .47 & .12 & $3.85^{\text {*** }}$ \\
5.7I (the 75th percentile; high) & .54 & .13 & $3.88^{* * * *}$ \\
6.21 (the 90th percentile; very high) & .57 & .15 & $3.84^{\text {*** }}$ \\
\hline
\end{tabular}

Note. LMX = leader-member exchange; LMCQ = leader-member conversational quality. $*_{p}<.05 . * * p<.01 . * * * p<.001$.

$\mathrm{OC}$ as the level of LMX increases. However, this result did not show us whether the association between LMCQ and OC was indeed statistically significant at each level of LMX. This question was addressed by testing the simple slope representing the relationship between LMCQ and OC at each of the five levels of LMX (the 10th, 25th, 50th, 75th, and 90th percentile). The results produced by PROCESS are presented in Table 3, demonstrating clearly that the slope at each level was statistically significant and the predictive effect of LMCQ on OC became stronger as the level of LMX increased from very low (the 10th percentile) to very high (the 90th percentile). Thus, our Hypothesis 2 was supported.

\section{Discussion}

Although considerable advancement has been made in the understanding of LMX and its antecedents and outcomes (Anand et al., 2011; Dulebohn et al., 2012), knowledge regarding the effects and processes of conversational practices in LMX is still quite limited. This study focused on the LMCQ construct and investigated its associations with LMX and OC. As defined earlier, LMCQ refers to conversational quality in a leader-member dyad characterized by efficiency, coordination, and accuracy in meaning interpretation and information transfer in the process of task accomplishment (Jian et al., 2014). Based on previous LMX research and social exchange theory, we hypothesized that LMCQ has a positive association with OC, and this association is moderated by LMX. The statistical results provided strong evidence supporting our hypotheses. In the following, we will explore the theoretical significance and practical implications of these results.

Theoretically, this study extends LMX theory and research. Although bearing the word exchange in its name, the LMX construct is, to a large extent, conceptualized as the overall relationship quality between leaders and members. It offers little insight into the actual communicative exchanges of a relational dyad or into the consequences of such communicative exchanges. Although it has long been established that LMX, or the overall relationship quality, has a significant association with OC (Dulebohn et al., 2012; Gerstner \& Day, 1997), whether and how communicative practices in 
leader-member dyads may be associated with such important outcomes as OC require further investigation and theorizing. Building on the construct of LMCQ (Jian et al., 2014), this study not only demonstrates that conversational quality matters in predicting employee commitment to the organization but also reveals how this predictive relationship varies across various levels of LMX quality. As the results indicated above, the positive predictive effects of conversational quality on commitment gradually increases as the relationship quality improves. It means that in better leader-member relationships, conversational quality matters more in predicting employee commitment to the organization. Thus, this finding adds to the LMX theory by going beyond the overall relationship quality and revealing the connection of individual attitudinal outcomes to specific communicative practices in the context of relationship functioning.

In addition, this finding opens up a new line of inquiry for future research, which is to theorize and test the detailed linkages between conversations and OC. At this point, we speculate that social exchange theory could offer some initial explanations. We suggested earlier in the article that leaders are representatives or proxies of an organization (Eisenberger et al., 1986). Commitment could be understood as an outcome of a social transaction that employees offer to leaders who work on behalf of the organization, in exchange for the leaders' support. Quality conversations may help enhance employee perceptions of support and feelings of communication satisfaction, both of which have been shown to be significant antecedents of OC (Cropanzano, Howes, Grandey, \& Toth, 1997; Van Vuuren et al., 2007). Moreover, existing LMX research has shown that higher LMX relationships involve more nonroutine problem solving, role negotiation, unstructured task assignments, and coaching (Fairhurst, 1993), which would exert greater demand on conversations than routine assignments and welldefined work roles. Presumably, higher quality conversations give employees a higher chance of success in these negotiations, and improve their ability to define and execute nonroutine tasks. This is then likely to result in higher job satisfaction, which in turn positively impacts OC (Mathieu \& Zajac, 1990). Thus, a complex process may underpin the association between LMCQ and OC and should be further conceptualized and empirically tested in future studies.

In addition, against a broader conceptual background, the findings of this study resonate with a growing perspective in organization studies - the communicative constitution of organization, also known as CCO (Cooren, Kuhn, Cornelissen, \& Clark, 2011; Putnam \& Nicotera, 2009; Taylor \& Van Every, 2000, 2011). The CCO perspective conceptualizes organizations as "ongoing and precarious accomplishments realized, experienced, and identified primarily - if not exclusively - in communication processes" (Cooren et al., 2011, p. 1150; emphasis in original). In other words, communication supplies the fundamental processes through which organizational relationships, structures, values, and strategies emerge as realities, are sustained, and change. From the CCO perspective, it is of interest to investigate whether and how OC as a normative and affective individual outcome, are produced through communicative practices, such as conversations. Research has suggested that communication satisfaction, information quality and flow, and message strategies be important 
communication factors (Carrière \& Bourque, 2009; Downs et al., 1995; Madlock, 2012; Van Vuuren et al., 2007; Varona, 1996) in relation to OC. Our study adds to this growing line of inquiry by demonstrating that LMCQ as an important aspect of communication practices has far-reaching predictive effects on OC. Although unable to specify the causal effect, the findings of this study could be a good starting point toward mapping out detailed constitutive processes that lead to attitudinal outcomes.

Three additional findings also deserve our attention. First, communication frequency between leaders and members, although not the focal construct examined in the study, demonstrated significant positive correlations with both predictor variables, LMCQ and LMX, and the outcome variable OC. This confirms its unquestionable value in the work context. Second, the significant negative correlation between race dissimilarity and communication frequency deserves attention. That is, leader-member dyads with different race compositions report lower levels of communication frequency than that of same-race dyads. This curious and unsettling finding calls for the attention of future research. Finally, the study provides further confirmation of the validity and reliability of the LMCQ scale as developed in Jian et al. (2014).

In spite of these significant findings, we want to acknowledge several limitations and suggest directions for future research. First, the data were based on members' recall and perception of LMCQ and LMX. Although members' perceptions have been shown to be significant predictors, our understanding can be enriched by three other approaches. One is to assess the effects of leaders' recall and perception of LMCQ and LMX. Second, building on research from the agreement approach on LMX that has revealed interesting results (e.g., Abu Bakar et al., 2014; Cogliser, Schriesheim, Scandura, \& Gardner, 2009; Markham, Yammarino, Murry, \& Palanski, 2010), the extent to which leaders and members agree on their reports can be examined. The third approach is to capture leader-member dialogue in real time and content-analyze its quality. This last approach is certainly most challenging because of the difficulty in obtaining real-time data due to access and time constraints. Our approach, although limited in scope, offers the initial step to analyze conversational quality and its predictive effects on other variables. Member's recall and perception has been shown to have its own value and significance in our understanding of the leader-member relational dynamic and outcomes.

The second limitation lies in the nature of a network sample. It limits the statistical generalizability of the findings. However, in comparison with studies that use representative samples from one or two organizations, as are often the case in LMX research, network samples as used in the present study provide the diversity of industry sectors and organizational types. Finally, the cross-sectional data are unable to reveal the developmental process in which conversational quality may evolve over time and shape individual, relational, and organizational outcomes. Future research would benefit greatly from a longitudinal and developmental approach.

In addition to the theoretical significance and limitations as discussed so far, the findings have significant implications for practicing managers and employees. At a general level, the findings direct attention of practitioners to conversational practices. Conventional wisdom, such as "talk is cheap," arbitrarily separates speech from action 
and prioritizes the latter, overlooking the fact that talk is action and gives meaning to action. The findings of this study suggest that conversational quality between leaders and members may be one of the consequential factors in maintaining a committed workforce.

More specifically, this study offers concrete behavioral guidance. First, the findings suggest that, as they form differential relationships with their employees, managers should be mindful that there is a greater demand on conversations with employees at higher levels of relationship quality. As we discussed earlier, nonroutine task assignments and role negotiations in higher LMX have to be facilitated by effective conversations. Being mindful of such demands on conversations is important because quality conversations may not happen spontaneously and could require planning, dedicated time, and focus. This awareness would help managers anticipate interactional challenges and allocate time and resources accordingly in order to achieve desired tasks and relational goals for both parties.

Second, the far-reaching predictive effects of LMCQ on OC may warrant the addition of conversational training to corporate training curricula as a valued skill. We believe that quality conversations can be improved through skill-based training and practice. For example, better coordination could be developed through practicing active listening and attention to nonverbal cues. Accuracy and efficiency could be improved by developing a co-orientation to each other's information needs and by enhancing the sensitivity to social and organizational contexts in which meanings of talk are interpreted. Thus, accuracy, efficiency, and coordination, the three aspects for evaluating conversational quality, could be used to guide the development of skills training sessions dedicated to enhancing conversational quality in the work context.

\section{Authors' Note}

A previous version of this article was presented at the 2013 Annual Conference of the International Communication Association, London, UK.

\section{Acknowledgments}

The authors would like to thank Dr. Michael Roloff and the anonymous reviewers for their valuable feedback.

\section{Declaration of Conflicting Interests}

The authors declared no potential conflicts of interest with respect to the research, authorship, and/or publication of this article.

\section{Funding}

The authors disclosed receipt of the following financial support for the research, authorship, and/or publication of this article: The presentation of this article was partially funded by the Graduate Faculty Travel Award Program at Cleveland State University. 


\section{References}

Abu Bakar, H., Jian, G., \& Fairhurst, G. (2014). The interactive effect of leader-member exchange agreement and relational demography on performance ratings. Asian Business Management, 13, 143-170. doi:10.1057/abm.2014.3

Aiken, L. S., \& West, S. G. (1991). Multiple regression: Testing and interpreting interactions. Thousand Oaks, CA: SAGE.

Anand, S., Hu, J., Liden, R. C., \& Vidyarthi, P. R. (2011). Leader-member exchange: Recent research findings and prospects for the future. In A. Bryman, D. Colllinson, K. Grint, B. Jackson, \& M. Uhl-Bien (Eds.), The SAGE handbook of leadership (pp. 311-325). London, England: SAGE.

Ashcraft, K. L., Kuhn, T. R., \& Cooren, F. (2009). Constitutional amendments: "Materializing" organizational communication. The Academy of Management Annals, 3(1), 1-64. doi:10.1080/19416520903047186

Bagozzi, R. P., \& Phillips, L. W. (1982). Representing and testing organizational theories: A holistic construal. Administrative Science Quarterly, 27, 459-489.

Barry, B., \& Crant, J. M. (2000). Dyadic communication relationships in organizations: An attribution/expectancy approach. Organization Science, 11, 648-664.

Bernerth, J. B., Armenakis, A. A., Feild, H. S., Giles, W. F., \& Walker, H. J. (2007). Leadermember social exchange (LMSX): Development and validation of a scale. Journal of Organizational Behavior, 28, 979-1003. doi:10.1002/job.443

Blau, P. M. (1964). Exchange and power in social life. New York, NY: John Wiley.

Boden, D. (1994). The business of talk: Organizations in action. Cambridge, UK: Polity.

Carrière, J., \& Bourque, C. (2009). The effects of organizational communication on job satisfaction and organizational commitment in a land ambulance service and the mediating role of communication satisfaction. Career Development International, 14, 29-49. doi:10.1108/13620430910933565

Cogliser, C. C., Schriesheim, C. A., Scandura, T. A., \& Gardner, W. L. (2009). Balance in leader and follower perceptions of leader-member exchange: Relationships with performance and work attitudes. The Leadership Quarterly, 20, 452-465. doi:10.1016/j.leaqua.2009.03.010

Cohen, J., Cohen, P., West, S. G., \& Aiken, L. S. (2013). Applied multiple regression/correlation analysis for the behavioral sciences (3rd ed.). New York, NY: Routledge.

Cooren, F., Kuhn, T., Cornelissen, J. P., \& Clark, T. (2011). Communication, organizing, and organization: An overview and introduction to the special issue. Organization Studies, 32, 1149-1170. doi:10.1177/0170840611410836

Cropanzano, R., Howes, J. C., Grandey, A. A., \& Toth, P. (1997). The relationship of organizational politics and support to work behaviors, attitudes, and stress. Journal of Organizational Behavior, 18, 159-180.

Cropanzano, R., \& Mitchell, M. S. (2005). Social exchange theory: An interdisciplinary review. Journal of Management, 31, 874-900. doi:10.1177/0149206305279602

Dansereau, F., Graen, G., \& Haga, W. J. (1975). A vertical dyad linkage approach to leadership within formal organizations: A longitudinal investigation of the role making process. Organizational Behavior and Human Performance, 13, 46-78. doi:10.1016/00305073(75)90005-7

De Ridder, J. A. (2004). Organizational communication and supportive employees. Human Resource Management Journal, 14, 20-30. doi:10.1111/j.1748-8583.2004.tb00124.x

Downs, C. W., Downs, A., Potvin, T., Varona, F., Gribas, J. S., \& Ticehurst, W. (1995, May). A cross-cultural comparison of relationships between organizational commitment and 
organizational communication. Paper presented at the International Communication Association Convention, Albuquerque, NM.

Dulebohn, J. H., Bommer, W. H., Liden, R. C., Brouer, R. L., \& Ferris, G. R. (2012). A meta-analysis of antecedents and consequences of leader-member exchange: Integrating the past with an eye toward the future. Journal of Management, 38, 1715-1759. doi:10.1177/0149206311415280

Eisenberger, R., Huntington, R., Hutchison, S., \& Sowa, D. (1986). Perceived organizational support. Journal of Applied Psychology, 71, 500-507.

Fairhurst, G. (1993). The leader-member exchange patterns of woman leaders in industry: A discourse analysis. Communication Monographs, 60, 321-351. doi:10.1080/03637759309376316

Fairhurst, G. (2007). Discursive leadership: In conversation with leadership psychology. Thousand Oaks, CA: SAGE.

Fix, B., \& Sias, P. M. (2006). Person-centered communication, leader-member exchange, and employee job satisfaction. Communication Research Reports, 23, 35-44. doi:10.1080/17464090500535855

Gerstner, C., \& Day, D. (1997). Meta-analytic review of leader-member exchange theory: Correlates and construct issues. Journal of Applied Psychology, 82, 827-844. doi: $10.1177 / 1742715006066023$

Graen, G. B., \& Uhl-Bien, M. (1995). Relationship-based approach to leadership: Development of a leader-member exchange (LMX) theory of leadership over 25 years: Applying a multilevel multi-domain perspective. Leadership Quarterly, 6, 219-247. doi:10.1016/10489843(95)90036-5

Harvey, P., \& Harris, K. (2010). Frustration-based outcomes of entitlement and the influence of supervisor communication. Human Relations, 63, 1639-1660. doi:10.1177/0018726710362923

Hayes, A. F. (2014). Introduction to mediation, moderation, and conditional process analysis: A regression-based approach. New York, NY: Guilford Press.

Jaccard, J., \& Turrisi, R. (2003). Interaction effects in multiple regression (2nd ed.). Thousand Oaks, CA: SAGE.

Jian, G. (2011). Articulating circumstance, identity, and practice: Toward a discursive framework of organizational changing. Organization, 18, 45-64. doi:10.1177/1350508410373672

Jian, G. (2014). Revisiting the association between LMX quality and perceived role stressors: Evidence of inverted-U relationship among immigrant employees. Communication Research, 41, 52-73. doi:10.1177/0093650211432468

Jian, G., Shi, X., \& Dalisay, F. (2014). Leader-member conversational quality: Scale development and validation through three studies. Management Communication Quarterly, 28, 375-403. doi:10.1177/0893318914533201

Kacmar, K. M., Witt, L. A., Zivnuska, S., \& Gully, S. M. (2003). The interactive effect of leader-member exchange and communication frequency on performance ratings. Journal of Applied Psychology, 88, 764-772.

Krone, K. J. (1991). Effects of leader-member exchange on subordinates' upward influence attempts. Communication Research Reports, 8, 9-18. doi:10.1080/08824099109359870

Lee, J. (2001). Leader-member exchange, perceived organizational justice, and cooperative communication. Management Communication Quarterly, 14, 574-589. doi:10.1177/0893318901144002

Lee, J., \& Jablin, F. M. (1995). Maintenance communication in supervisor-subordinate work relationships. Human Communication Research, 22, 220-257. doi:10.1177/0021943612436972 
Liden, R. C., \& Maslyn, J. M. (1998). Multidimensionality of leader-member exchange: An empirical assessment through scale development. Journal of Management, 24, 43-72. doi:10.1016/S0149-2063(99)80053-1

Madlock, P. E. (2012). The influence of cultural congruency, communication, and work alienation on employee satisfaction and commitment in Mexican organizations. Western Journal of Communication, 76, 380-396.

Markham, S. E., Yammarino, F. J., Murry, W. D., \& Palanski, M. E. (2010). Leader-member exchange, shared values, and performance: Agreement and levels of analysis do matter. The Leadership Quarterly, 21, 469-480. doi:10.1016/j.leaqua.2010.03.010

Mathieu, J. E., \& Zajac, D. M. (1990). A review and meta-analysis of the antecedents, correlates, and consequences of organizational commitment. Psychological Bulletin, 108, 171-194.

Mowday, R. T., Steers, R. M., \& Porter, L. W. (1979). The measurement of organizational commitment. Journal of Vocational Behavior, 14, 224-247. doi:10.1016/00018791(79)90072-1

Mueller, B. H, \& Lee, J. (2002). Leader-member exchange and organizational communication satisfaction in multiple contexts. Journal of Business Communication, 39, 220-244. doi:10.1177/002194360203900204

Olufowote, J. O., Miller, V. D., \& Wilson, S. R. (2005). The interactive effects of role change goals and relational exchanges on employee upward influence tactics. Management Communication Quarterly, 18, 385-403. doi:10.1177/0893318904270743

Podsakoff, P. M., MacKenzie, S. B., Lee, J.-Y., \& Podsakoff, N. P. (2003). Common method biases in behavioral research: A critical review of the literature and recommended remedies. Journal of Applied Psychology, 88, 879-903. doi:10.1037/0021-9010.88.5.879

Putnam, L. L., \& Nicotera, A. M. (Eds.). (2009). Building theories of organization: The constitutive role of communication. New York, NY: Routledge.

Rogers, W. M. (2009). Theoretical and mathematical constraints of interactive regression models. Organizational Research Methods, 5, 212-230. doi:10.1177/1094428102005003002

Scandura, T. A., \& Graen, G. B. (1984). Moderating effects of initial leader-member exchange status on the effects of a leadership intervention. Journal of Applied Psychology, 69, 428-436.

Sias, P. M. (2005). Workplace relationship quality and employee information experiences. Communication Studies, 56, 375-395. doi:10.1080/10510970500319450

Sin, H.-P., Nahrgang, J. D., \& Morgeson, F. P. (2009). Understanding why they don't see eye to eye: An examination of leader-member exchange (LMX) agreement. Journal of Applied Psychology, 94, 1048-1057. doi:10.1037/a0014827

Taylor, J., \& Van Every, E. J. (2000). The emergent organization: Communication as its site and surface. New York, NY: Psychology Press.

Taylor, J., \& Van Every, E. J. (2011). The situated organization: Case studies in the pragmatics of communication research. New York, NY: Routledge.

Tsui, A. S., \& Gutek, B. A. (1999). Demographic differences in organizations: Current research and future directions. New York, NY: Lexington Press.

Tsui, A. S., \& O'Reilly, C. A., III. (1989). Beyond simple demographic effects: The importance of relational demography in superior-subordinate dyads. Academy of Management Journal, 32, 402-423.

Tsui, A. S., Porter, L. W., \& Egan, T. D. (2002). When both similarities and dissimilarities matter: Extending the concept of relational demography. Human Relations, 55, 899-929. doi: $10.1177 / 0018726702055008176$ 
Van Breukelen, W., Schyns, B., \& Le Blanc, P. (2006). Leader-member exchange theory and research: Accomplishments and future challenges. Leadership, 2, 295-316. doi:10.1177/1742715006066023

Van Vuuren, M., De Jong, M. D. T., \& Seydel, E. R. (2007). Direct and indirect effects of supervisor communication on organizational commitment. Corporate Communications: An International Journal, 12, 116-128. doi:10.1108/13563280710744801

Varona, F. (1996). Relationship between communication satisfaction and organizational commitment in three Guatemalan Organizations. The Journal of Business Communication, 33, 111-140. doi:10.1177/002194369603300203

Waldron, V. (1991). Achieving communication goals in superior-subordinate relationships: The multi-functionality of upward maintenance tactics. Communication Monographs, 58, 289306. doi:10.1080/03637759109376231

Waldron, V., \& Sanderson, J. (2011). The role of subjective threat in upward influence situations. Communication Quarterly, 59, 239-254. doi:10.1080/01463373.2011.563444

\section{Author Biographies}

Guowei Jian (PhD, University of Colorado, 2003) is an associate professor in the School of Communication at Cleveland State University, Cleveland, Ohio, USA. His research interests include organizational communication, leadership, and intercultural communication. He also studies work participation and civic engagement. His research appears in Communication Research, Communication Monographs, Organization, Management Communication Quarterly, Communication Studies, Discourse \& Communication, and The Handbook of Business Discourse, among others.

Francis Dalisay ( $\mathrm{PhD}$, Washington State University, 2010) is an assistant professor in the School of Communications at the University of Hawai'i-Manoa, Honolulu, Hawaii, USA. His research interests include communication effects on public attitudes, public engagement, and socialization. His research appears in Journalism \& Mass Communication Quarterly, the International Journal of Public Opinion Research, Communication Research Reports, and Communication Quarterly, among others. 